REALA, número 14, octubre de 2020

Sección: ARTÍCULOS

Recibido: 22-08-2020

Modificado: 18-09-2020

Aceptado: 23-09-2020

DOI: https://doi.org/10.24965/reala.i14.10854

Páginas: 69-87

\title{
La progresiva apertura de los servicios públicos locales a la libre competencia
}

\section{The progressive opening of local public services to free competition}

\author{
Roberto Galán Vioque \\ Universidad de Sevilla (España) \\ ORCID: https://orcid.org/0000-0002-8215-3531 \\ rgvioque@us.es
}

\section{NOTA BIOGRÁFICA}

Profesor Titular de Universidad del Departamento de Derecho Administrativo de la Universidad de Sevilla (2002). Ha sido consultor internacional en el Programa Municipios Democráticos de la Unión Europea en Guatemala ALA/2000/3061 DTA GUA/B7-310/00/0020 (2006) y vocal Asesor del Gabinete de la Presidencia del Gobierno de España (2007 y 2008). Desde 2018 es el Director del Centro de Recursos para el Aprendizaje y la Investigación de la Universidad de Sevilla. Investigador principal del Proyecto de Investigación DER2017-86637-C3-1-P Hacia una nueva regulación de las energías renovables dentro del mercado energético que a su vez coordina al Proyecto Desafíos jurídicos de la transición energética (DEJUTRANSEN).

\section{RESUMEN}

En este trabajo se analizan los efectos jurídicos que la penetración del principio de libre competencia tiene sobre los servicios públicos locales de carácter económico. Aunque ha habido servicios que han sido liberalizados (los funerarios y los mataderos), sigue habiendo actividades como el abastecimiento de aguas y la recogida de aguas residuales, los transportes urbanos y recogida de basuras que se mantienen en la órbita de los servicios públicos. A estas actividades les resulta aplicable el principio de libre competencia en la medida que las restricciones al funcionamiento del mercado que suponen deben ajustarse a las misiones específicas que tenga asignadas como servicio público.

La libre competencia juega un papel decisivo cuando se trata de servicios públicos locales que se prestan en régimen de concurrencia con la iniciativa privada y también en relación con la participación privada en la gestión indirecta de los servicios públicos a través de la contratación pública.

\section{PALABRAS CLAVE}

Contratación pública; Derecho de la Unión Europea; iniciativa pública económica; liberalización; libre competencia; servicios públicos locales.

\footnotetext{
ABSTRACT

This paper analyzes the legal effects that the penetration of the principle of free competition has on local public economic services. Although there have been services that have been liberalized (funeral services or municipal slaughterhouses), there are still activities such as water supply and wastewater collection, urban transport and garbage collection that remain in the orbit of public services. The principle of free competition reaches them in order to force that the restrictions on the operation of the market must be adjusted to the specific missions assigned to it as a public service.
} 
REALA. Nueva Época - N. 14, octubre 2020 - ISSN: 1989-8975 - DOI: https://doi.org/10.24965/reala.i14.10854 - [Págs. 69-87]

La progresiva apertura de los servicios públicos locales a la libre competencia

Free competition plays as well a decisive role when it comes to local public services that are provided concurrently with private initiative and also in relation to private participation in the indirect management of public services through public procurement.

\title{
KEYWORDS
}

European Union law; liberalization; free competition; economic public initiative; public procurement; local public services.

\begin{abstract}
SUMARIO
INTRODUCCIÓN. 1. VICISITUDES EN LA REGULACIÓN DE LOS SERVICIOS PÚBLICOS LOCALES TRAS LA CONSTITUCIÓN DE 1978 Y LA INCORPORACIÓN DE ESPAÑA A LA COMUNIDAD ECONÓMICA EUROPEA. 1.1. LA CONFUSA RECEPCIÓN DE LOS SERVICIOS PÚBLICOS EN LA LBRL. 1.2. EL IMPACTO DEL PROCESO LIBERALIZADOR DE LAACTIVIDAD ECONÓMICA POR PARTE DE LA HOY UNIÓN EUROPEA SOBRE LOS SERVICIOS PÚBLICOS LOCALES. 1.3. LA LRSAL COMO VÍA PARA LA APLICACIÓN DE LOS PRINCIPIOS DE ESTABILIDAD PRESUPUESTARIA Y SOSTENIBILIDAD FINANCIERA A LOS SERVICIOS PÚBLICOS LOCALES. 2. ¿SE HA PRODUCIDO UNA LIBERALIZACIÓN DE LOS SERVICIOS PÚBLICOS LOCALES EN LAS ÚLTIMAS DÉCADAS? 2.1. LA LIBERALIZACIÓN DE LOS SERVICIOS FUNERARIOS LLEVADA A CABO POR EL REAL DECRETO-LEY 7/1996, DE 7 JUNIO, DE MEDIDAS URGENTES DE CARÁCTER FISCAL Y DE FOMENTO Y LIBERALIZACIÓN DE LAACTIVIDAD ECONÓMICA. 2.2. LA DESCONCERTANTE DESREGULACIÓN DE LOS MERCADOS Y LOS MATADEROS MUNICIPALES EFECTUADA POR LA LRSAL. 3. LA DISCUTIBLE CONCURRENCIA DE SERVICIOS PÚBLICOS MUNICIPALES CON LA INICIATIVA PRIVADA. 3.1. LA APLICACIÓN DE LAS NORMAS SOBRE COMPETENCIA A LOS SERVICIOS PÚBLICOS LOCALES. 3.2. EL CASO PARADIGMÁTICO DE LAS INSTALACIONES DEPORTIVAS DE USO PÚBLICO. 4. LIBRE CONCURRENCIA EN EL ACCESO A LA GESTIÓN INDIRECTA DE LOS SERVICIOS PÚBLICOS LOCALES COMO MEDIO PARA FAVORECER LA LIBRE COMPETENCIA. CONCLUSIONES. REFERENCIAS BIBLIOGRÁFICAS.
\end{abstract}

\section{INTRODUCCIÓN}

El título del presente trabajo puede parecer a simple vista contradictorio. Si algo caracteriza a los servicios públicos es precisamente que constituyen una excepción al funcionamiento de los mercados donde no se tiene que respetar la libre competencia. Pero también es cierto que desde finales del siglo pasado ha habido una tendencia hacía la liberalización de los llamados servicios públicos económicos que ha venido impulsado desde las instituciones de la hoy Unión Europea.

Los servicios públicos locales de corte económico han resistido mejor que otros el embate de esta tendencia liberalizadora. Se liberalizaron en 1996 los servicios funerarios y en 2013 los mercados y los mataderos municipales. Pero el grueso de sus prestaciones como el abastecimiento de agua y recogida de aguas residuales, la recogida y el tratamiento de residuos y el transporte urbano de pasajeros sigue manteniendo aún hoy su condición tradicional como servicio público.

El objeto del presente estudio es analizar, a partir de los cambios que se han producido en la regulación de los servicios públicos locales en la legislación de régimen local en los últimos años, cómo la libre competencia ha ido penetrando en el interior de aquellas actividades y servicios que nuestro ordenamiento deja en la órbita de las Entidades locales.

\section{VICISITUDES EN LA REGULACIÓN DE LOS SERVICIOS PÚBLICOS LOCALES TRAS LA CONSTITUCIÓN DE 1978 Y LA INCORPORACIÓN DE ESPAÑA A LA COMUNIDAD ECONÓMICA EUROPEA}

Hay pocos conceptos más ambiguos que el del servicio público y ello a pesar de que se trata de una categoría jurídica central del Derecho Administrativo. Esta ambigüedad del concepto de servicio público se refleja en el propio texto constitucional que utiliza esta noción en su artículo 106.2 en un sentido amplio, donde servicio público equivale genéricamente a cualquier actuación administrativa, cuando se refiere a 
la responsabilidad patrimonial de las Administraciones Públicas por las lesiones que sean «consecuencia del funcionamiento de los servicios públicos» y que, por el contrario, lo contempla de un modo mucho más concreto y restringido cuando en el segundo inciso del artículo 128.2 regula expresamente la denominada publicatio de algunas actividades de forma que «[m]ediante ley se podrá reservar al sector público [...] servicios esenciales, especialmente en caso de monopolio».

En el caso de los servicios públicos locales llovía sobre mojado porque los Municipios habían tenido que hacer frente históricamente a necesidades muy diversas de sus vecinos que se fueron encajando dentro de un cada vez más amorfo y amplio concepto de servicio público. Lo que explica la poco precisa recepción que de la figura del servicio público se hizo en la Ley $7 / 1985$, de 2 de abril, reguladora de las bases del régimen local (en lo sucesivo LBRL).

\subsection{La confusa recepción de los servicios públicos en la LBRL}

Hubo que esperar a que se cerrase el mapa autonómico, con la aprobación de los últimos Estatutos de Autonomía en el año 1983, para que las Cortes Generales afrontarán la primera regulación integral del régimen local español posterior a la Constitución española de 1978. La LBRL, como no podía ser de otra forma, le dedicaría una atención importante a la regulación de los servicios públicos locales, aunque lo hiciera de una manera ciertamente confusa (Ballesteros Fernández, 2001: 92 y Del Guayo Castiella, 2004: 95).

Los servicios públicos locales aparecerían en la LBRL hasta en tres formas distintas. En primer lugar, y como suele ser habitual en este tipo de normas, en su artículo 25.1 se estableció una amplia y genérica potestad de los Municipios para prestar servicios públicos. Este precepto disponía, en su versión original, que el «Municipio, para la gestión de sus intereses y en el ámbito de sus competencias, puede promover toda clase de actividades y prestar cuantos servicios públicos contribuyan a satisfacer las necesidades y aspiraciones de la comunidad vecinal». En principio los Municipios, por lo tanto, no tenían ningún límite para crear servicios públicos en el ámbito de sus competencias que se recogían en un amplio listado en el apartado siguiente. Pero es que, además, en su artículo 28 , ya derogado ${ }^{1}$, se les facultaba también para «realizar actividades complementarias de las propias de otras Administraciones públicas y, en particular, las relativas a la educación, la cultura, la promoción de la mujer, la vivienda, la sanidad y la protección del medio ambiente» con los que se ensanchaba aún más el ámbito de los posibles servicios públicos municipales. En consonancia con esta generosa regulación en el artículo 85.1 de la LBRL se consideraban como servicios públicos «cuantos tienden a la consecución de los fines señalados como de la competencia de las Entidades locales» ${ }^{2}$.

La segunda versión de los servicios públicos locales sería la de los llamados servicios municipales obligatorios. En el artículo 26.1 de la LBRL se establecieron una serie de servicios que tenían que prestar forzosamente todos los Municipios ${ }^{3}$, que se iban incrementando en función de que la población superase los $5.000^{4}, 20.000^{5}$ y $50.000^{6}$ habitantes, respectivamente. En este elenco de servicios obligatorios se mezclaban actividades de muy distinta naturaleza. Junto a funciones propiamente administrativas de los Municipios como la limpieza viaria, el control de alimentos y bebidas, la protección civil, la prevención y extinción de incendios y la protección del medio ambiente, se incluían infraestructuras de carácter públicas como los cementerios, el alumbrado público, el alcantarillado, el acceso a los núcleos de población, la pavimentación de las vías públicas, las bibliotecas públicas, los parques públicos y las instalaciones deportivas de uso público. Tan solo el abastecimiento domiciliario de agua potable, el tratamiento y recogida de residuos, los mercados, la prestación de servicios sociales, los mataderos y el transporte colectivo urbano de viajeros encajaban dentro de la noción clásica de servicio público. Este listado de servicios obligatorios,

1 Este precepto fue suprimido por el artículo 1. Once de la Ley 27/2013, de 27 de diciembre, de racionalización y sostenibilidad de la Administración Local (LRSAL).

2 La Ley 57/2003, de 16 de diciembre, de Medidas para la modernización del gobierno local recortó el alcance de esta facultad de forma que a partir de ella sólo se podrán considerar como servicios públicos locales aquellos servicios «que prestan las entidades locales en el ámbito de sus competencias».

3 Alumbrado público, cementerio, recogida de residuos, limpieza viaria, abastecimiento domiciliario de agua potable, alcantarillado, acceso a los núcleos de población, pavimentación de las vías públicas y control de alimentos y bebidas.

4 Parque público, biblioteca pública, mercado y tratamiento de residuos.

5 Protección civil, prestación de servicios sociales, prevención y extinción de incendios, instalaciones deportivas de uso público y matadero.

6 Transporte colectivo urbano de viajeros y protección del medio ambiente. 
salvo el caso de los mataderos ${ }^{7}$ y los mercados $^{8}$ que desaparecerían de él, se ha mantenido de forma prácticamente invariable ${ }^{9}$.

El carácter obligatorio de estos servicios se traduce en el derecho que tienen los vecinos ex artículo 18.1 g) de la LBRL a «[e]xigir la prestación y, en su caso, el establecimiento del correspondiente servicio público, en el supuesto de constituir una competencia municipal propia de carácter obligatorio». Previsión que se refuerza con lo que se establece en la Ley de Haciendas Locales, cuyo texto refundido está aprobado por medio del Real Decreto Legislativo 2/2004, de 5 marzo, que en su artículo 170.2 b) únicamente permite entablar reclamaciones contra los presupuestos municipales, además de por defectos formales en su aprobación o por manifiesta insuficiencia de los ingresos o de los gastos presupuestados, por «omitir el crédito necesario para el cumplimiento de obligaciones exigibles a la entidad local, en virtud de precepto legal o de cualquier otro título legítimo». Solo en los casos en que resultara imposible o de muy difícil cumplimiento la prestación de los servicios obligatorios la Comunidad Autónoma podría dispensarle de esta obligación ${ }^{10}$.

La LBRL fue mucho más fiel al mecanismo de la publificación ope legis de servicios esenciales, contemplado en el artículo 128.2 de la Constitución, en su tercera versión de la figura del servicio público. Como las Entidades locales carecen de potestad legislativa la reserva de servicios esenciales a su favor la tienen que hacer las Cortes Generales o en su caso los Parlamentos autonómicos. Con esta finalidad se incluyó en el artículo 86.3 un precepto en el que se procedió a declarar «la reserva en favor de las Entidades locales de las siguientes actividades o servicios esenciales: abastecimiento y depuración de aguas; recogida, tratamiento y aprovechamiento de residuos; suministro de gas y calefacción; mataderos, mercados y lonjas centrales; transporte público de viajeros; servicios mortuorios». Añadiéndose que el «Estado y las Comunidades Autónomas, en el ámbito de sus respectivas competencias, podrán establecer, mediante Ley, idéntica reserva para otras actividades y servicios». Estos servicios quedaban reservados a las Entidades locales que si querían prestarlos en régimen de monopolio necesitaban, además, una autorización del órgano de gobierno de su Comunidad Autónoma. Todas estas actividades o servicios reservados se correspondían con lo que tradicionalmente se conocía como servicios públicos de carácter económicos ya que conllevaban la prestación de unos servicios a los vecinos a cambio del correspondiente pago ${ }^{11}$.

Entre estas tres modalidades de servicios públicos locales había además una notoria desconexión. Había servicios reservados como el del suministro de gas y calefacción que no figuraban entre las competencias de los Municipio o existían servicios obligatorios como el de las instalaciones deportivas de uso público ${ }^{12}$ que no se había reservado a las entidades locales. Esta falta de coherencia de la LBRL se puede explicar por el carácter expansivo que la figura de los servicios públicos tenía en 1985.

\subsection{El impacto del proceso liberalizador de la actividad económica por parte de la hoy Unión Europea sobre los servicios públicos locales}

Ninguna de las actividades económicas que fueron liberalizadas por lo que hoy es la Unión Europea a partir de la última década del siglo pasado (Telecomunicaciones, transportes, energías, servicios postales, etc...) afectó a los servicios públicos económicos reservados a las Entidades locales españolas. Ni siquiera el del «suministro de gas» que figuraba en el antiguo artículo 86.3 de la LBRL y que fue, con una curiosa técnica legislativa, derogado por la Ley 34/1998, de 7 de octubre, del Sector de Hidrocarburos ${ }^{13}$, por la que se traspuso precisamente la Directiva 98/30/CE del Parlamento Europeo y del Consejo, de 22 de junio de 1998, relativa a normas comunes para el mercado interior del gas, que fue la norma que liberalizó el suministro de gas. En realidad se trataba de una previsión de muy escaso alcance porque, como ha destacado la doctrina (Salas, 1990 y Del Guayo Castiella, 2004: 95), ya antes la Ley 10/1987, de 15 de junio, de disposiciones bá-

7 Art. 24 del Real Decreto-ley 7/1996, de 7 junio, de Medidas urgentes de carácter fiscal y de fomento y liberalización de la actividad económica.

8 Art. 1. Nueve LRSAL.

9 La LRSAL sustituyó la genérica referencia de la prestación de servicios sociales por la más acotada de «evaluación e información de situaciones de necesidad social y la atención inmediata a personas en situación o riesgo de exclusión social» (Art. 1. Nueve)

10 Art. 26.2 LBRL.

11 En la actualidad han quedado reducidos a «abastecimiento domiciliario y depuración de aguas; recogida, tratamiento y aprovechamiento de residuos; $y$ transporte público de viajeros» y se encuentran ubicados ahora en el artículo 86.2 LBRL.

12 Art. 26.2 a) LBRL.

13 Su disposición derogatoria única e) derogó el «artículo 86.3 de la Ley 7/1985, de 2 de abril, y disposiciones concordantes, en lo que se refieren al suministro de gas». 
sicas para un desarrollo coordinado de actuaciones en el sector de combustibles gaseosos había efectuado una reserva del servicio público de suministro de combustibles gaseosos por canalización en favor del Estado y las Comunidades Autónomas. Para conciliar esta reserva legal con la del artículo 86.3 de la LBRL su artículo 1 in fine permitió a los Municipios asumir su prestación en el momento en que se fueran a implantar este servicio en su término municipal ${ }^{14}$. Si no lo hacían pasaban a manos del Estado o de las Comunidades Autónomas.

Como es sabido, este proceso liberalizador trajo consigo una nueva configuración jurídica de los servicios públicos (Parejo Alfonso 2004: 56 y Carlon Ruiz, 2016: 238) que se construyó en torno al nuevo concepto de servicios de interés general que englobaban tanto a los que se denominan servicios no económico de interés general, que se corresponderían con los servicios de autoridad que en nuestro ordenamiento jurídico sería el ejercicio de funciones públicas por parte de la Administración y los servicios de solidaridad que abarcaría a nuestro servicios públicos asistenciales como la sanidad, la educación y los servicios sociales, como a los servicios de interés económico general que coincidirían esencialmente con alguno de nuestros tradicionales servicios públicos económicos.

Estas actividades económicas pasaron a prestarse en régimen de libre competencia, a cambio de que se les pudiera imponer a las empresas que entraran en estos nuevos mercados obligaciones de servicio público. En relación con estos últimos servicios de interés económico general el artículo 106.2 del Tratado de Funcionamiento de la Unión Europea (TFUE) establece una importante limitación ya que las empresas encargadas de su gestión «quedarán sometidas a las normas de los Tratados, en especial a las normas sobre competencia, en la medida en que la aplicación de dichas normas no impida, de hecho o de derecho, el cumplimiento de la misión específica a ellas confiada». Con lo que claramente se quería reforzar el respeto a las normas sobre competencia en el ámbito de estos servicios.

Resulta curioso pero esta construcción del Derecho de la Unión Europea se ha incorporado a la propia regulación de los servicios públicos locales como se hizo en la Ley 5/2010, de 11 junio, de Autonomía Local de Andalucía (Montoya Martín, 2010: 149) que le dedica un capítulo a regular los Servicios locales de interés general y su régimen jurídico ${ }^{15}$. Precisamente para cumplir con las normas sobre competencia su artículo 44 establece que cuando «las empresas a las que las administraciones locales hayan atribuido la gestión de servicios de interés económico general o hayan concedido derechos especiales o exclusivos realicen además otras actividades, actúen en régimen de competencia y reciban cualquier tipo de compensación por el servicio público, estarán sujetas a la obligación de la llevanza de cuentas separadas, de información sobre los ingresos y costes correspondientes a cada una de las actividades y sobre los métodos de asignación empleados, en los términos establecidos por la legislación estatal y por el Derecho europeo».

Por último, hay que tener en cuenta que ya se han superado los primeros planteamientos, tanto doctrinales como jurisprudenciales (Campos Sánchez-Bordona, 2004: 75), que sostenían que los servicios públicos locales por su alcance limitado no podían quedar afectados por las normas sobre competencia de la Unión Europea. El propio, en aquella época, Tribunal de Justicia de las Comunidades Europeas se encargó de echar por tierra estos planteamiento en su paradigmática sentencia, de su Pleno, recaída en el Caso Altmark Trans y Regierungspräsidium Magdeburg contra Altmark Trans y Regierungspräsidium Magdeburg, de 24 julio $2003^{16}$ donde rechazó con rotundidad que las normas sobre ayudas de Estado no se puedan aplicar al servicio público de transporte de viajeros de ámbito local, afirmando tajantemente en su parágrafo $82 .^{\circ}$ que:

«...el segundo requisito para la aplicación del artículo 92, apartado 1, del Tratado, según el cual la ayuda debe poder afectar a los intercambios entre Estados miembros, no depende del carácter local o regional de los servicios de transporte prestados ni de la importancia del ámbito de actividad de que se trate».

Antes ya había sostenido algo obvio, que la concesión de ayudas a empresa de transporte público de viajero de ámbito urbano afectaba a la posibilidad de que empresas de otro Estado miembro pudiera prestar este servicio. También había recordado que la Comisión Europea había dejado constancia en el proceso de que varios Estados miembros habían empezado a abrir, desde 1995, este mercado a la competencia, lo que

14 El artículo 6 de esta Ley establecía el procedimiento para asumir este servicio público.

15 Capítulo que se inserta en su Título II, Los servicios y la iniciativa económica locales.

16 TJCE\2003\218. 
REALA. Nueva Época - N.o 14, octubre 2020 - ISSN: 1989-8975 - DOI: https://doi.org/10.24965/reala.i14.10854 - [Págs. 69-87]

La progresiva apertura de los servicios públicos locales a la libre competencia

Roberto Galán Vioque

había traído como consecuencia que existieran ya varias empresas que prestaban servicios de transporte urbano en más de un país de la Unión Europea ${ }^{17}$.

\subsection{La LRSAL como vía para la aplicación de los principios de estabilidad presupuestaria y sostenibilidad financiera a los servicios públicos locales}

El principio de estabilidad presupuestaria, que también tiene su origen en las Instituciones de la Unión Europea, ha supuesto una importante transformación de los servicios públicos (Fernández Rodríguez, 2016) de modo que a sus tradicionales principios de igualdad y universalidad, continuidad, asequibilidad, calidad y mutabilidad se le ha añadido ahora el que podría denominarse como el de la sostenibilidad de los servicios públicos.

Al mismo tiempo que se creó la moneda única común se aprobó el Pacto de Estabilidad y Crecimiento de 1997 que establecía un mecanismo de control del gasto público de los Estados miembros y que en nuestro país dio lugar a su vez a la aprobación de una primera regulación de la estabilidad presupuestaria ${ }^{18}$. Tras la crisis económica, anterior a la creada ahora por la pandemia de la COVID 19, estos controles se exacerbaron con la aprobación del Tratado de Estabilidad, Coordinación y Gobernanza en la Unión Económica y Monetaria ${ }^{19}$, conocido como el Pacto Fiscal. Este giro de la Unión Europea hacia las denominadas políticas de austeridad fiscal se plasmó en España en la modificación, en septiembre de 2011, de la Constitución para consagrar al máximo rango jurídico el principio de estabilidad presupuestaria ${ }^{20}$, que meses más tarde vino seguida de la aprobación de la vigente Ley Orgánica 2/2012, de 27 de abril, de Estabilidad Presupuestaria y Sostenibilidad Financiera en la que se concretaron los mecanismos de disciplina fiscal y presupuestaria aplicable a todas las Administraciones Públicas españolas, incluidas las Entidades locales.

Poco tiempo después se aprobó la muy polémica Ley 27/2013, de 27 de diciembre, de racionalización y sostenibilidad de la Administración Local (LRSAL) que tendría como objetivo principal e inequívoco el de adaptar «la normativa básica en materia de Administración local para la adecuada aplicación de los principios de estabilidad presupuestaria, sostenibilidad financiera o eficiencia en el uso de los recursos públicos locales» ${ }^{21}$. Esta Ley cambió la redacción del artículo 25 para limitar considerablemente la potestad de los Municipios para crear servicios públicos. El nuevo artículo 25.3 dispone ahora que las «competencias municipales en las materias enunciadas en este artículo se determinarán por Ley debiendo evaluar la conveniencia de la implantación de servicios locales conforme a los principios de descentralización, eficiencia, estabilidad y sostenibilidad financiera», añadiendo en el apartado siguiente que la Ley que atribuya la competencia «deberá ir acompañada de una memoria económica que refleje el impacto sobre los recursos financieros de las Administraciones Públicas afectadas y el cumplimiento de los principios de estabilidad, sostenibilidad financiera y eficiencia del servicio o la actividad. La Ley debe prever la dotación de los recursos necesarios para asegurar la suficiencia financiera de las Entidades Locales sin que ello pueda conllevar, en ningún caso, un mayor gasto de las Administraciones Públicas». Y, por si fueran pocas todas estas exigencias, se exige además un informe preceptivo del entonces Ministerio de Hacienda y Administraciones Públicas ${ }^{22}$, en el que se acredite el cumplimiento de estos criterios. La intención del Legislador era clara. La creación de

17 En base a esta doctrina la reciente sentencia del Tribunal de Justicia de la Unión Europea, recaída en el Caso Istituto nazionale della previdenza sociale (INPS) contra Azienda Napoletana Mobilità SpA, de 29 julio 2019 (JURI20191229544) confirmó la Decisión 2000/128/CE de la Comisión, de 11 de mayo de 1999 que había considerado aplicable el régimen de las ayudas de Estado a las reducciones de gastos sociales concedidas a una empresa adjudicataria de los servicios de transporte público local en régimen de exclusividad.

18 Se trató de la Ley 18/2001, de 12 de diciembre, de Estabilidad Presupuestaria y de la Ley orgánica 5/2001, de 13 de diciembre, complementaria de la Ley General de Estabilidad Presupuestaria.

19 Incorporado a nuestro ordenamiento jurídico mediante la Ley orgánica 3/2012, de 25 de julio, por la que se autoriza la ratificación por España del Tratado de Estabilidad, Coordinación y Gobernanza en la Unión Económica y Monetaria entre el Reino de Bélgica, la República de Bulgaria, el Reino de Dinamarca, la República Federal de Alemania, la República de Estonia, Irlanda, la República Helénica, el Reino de España, la República Francesa, la República Italiana, la República de Chipre, la República de Letonia, la República de Lituania, el Gran Ducado de Luxemburgo, Hungría, Malta, el Reino de los Países Bajos, la República de Austria, la República de Polonia, la República Portuguesa, Rumanía, la República de Eslovenia, la República Eslovaca, la República de Finlandia y el Reino de Suecia. Con la única excepción, del Reino Unido que entonces figuraba entre los 28 Estados miembros de la Unión Europea.

2015210 Reforma del artículo 135 de la Constitución Española, de 27 de septiembre de 2011 publicada en el Boletín Oficial del Estado, núm. 233, de 27 de septiembre de 2011, pág. 101.931.

21 Como se proclama enfáticamente en el primer párrafo de su Exposición de Motivos.

22 Actual Ministerio de Hacienda de conformidad con el Real Decreto 2/2020, de 12 de enero, por el que se reestructuran los departamentos ministeriales. 
un servicio público local pasó de ser una facultad genérica municipal a tener que estar expresamente contemplada en una la Ley y a tener que ajustarse estrictamente al cumplimiento de los principios de equilibrio presupuestario y de sostenibilidad financiera (Villar Rojas, 2016).

En su obsesión por garantizar estos principios se introdujo en el artículo 26.2 de la LRSAL, con una notable imprecisión (Barrero Rodríguez, 2016: 38), el polémico concepto del coste efectivo de los servicios que sería supuestamente aquel en el que se podrían prestar los servicios públicos locales de la forma más eficiente. Sólo si el Municipio acredita que los puede prestar a un coste menor a aquel en el que lo harían las Diputaciones provinciales podría asumir su prestación. Parece lógico pensar que la forma en que las Diputaciones provinciales pueden conseguir este menor coste pasa por externalizar en empresas privadas, por vía contractual, la prestación de estos servicios públicos. Con lo que se limitaría considerablemente el margen que tendrían los Municipios para gestionar directamente sus servicios públicos, al mismo tiempo que se ensanchaba la posibilidad de que la iniciativa privada a través de una licitación pública asumiera su prestación (Boix Palop, 2004: 44). No obstante, la potestad de coordinación de la Administración General del Estado en la determinación de estos costes efectivos de los servicios públicos locales que este mismo precepto contemplaba fue declarada inconstitucional por la STC 111/2016, de 9 junio, por considerar que vulneraba las competencias de las Comunidades Autónomas ${ }^{23}$, con lo que se redujo considerablemente su alcance.

Más allá de las competencias propias o que le fueran delegadas a las Entidades locales el nuevo y alambicado artículo 7.4 de la LBRL solo les permitía ejercer otras competencias cuando «no se ponga en riesgo la sostenibilidad financiera del conjunto de la Hacienda municipal, de acuerdo con los requerimientos de la legislación de estabilidad presupuestaria y sostenibilidad financiera y no se incurra en un supuesto de ejecución simultánea del mismo servicio público con otra Administración Pública» y además se dispongan de los informes preceptivos y vinculantes de la Administración sectorial competente que acredite que no se van a producir duplicidades administrativas y de aquella que ejerza la tutela financiera sobre la sostenibilidad financiera de las nuevas competencias.

Además de estas medidas, la LRSAL, como ya antes hicieran otras leyes, reduciría también el elenco de actividades y servicios reservados a las Entidades locales por la LBRL.

\section{2. ¿SE HA PRODUCIDO UNA LIBERALIZACIÓN DE LOS SERVICIOS PÚBLICOS LOCALES EN LAS ÚLTIMAS DÉCADAS?}

Si se compara el listado de los servicios y actividades esenciales que el actual artículo 86.2 de la LBRL reserva en favor de las Entidades locales con el que aparecía en esta Ley inicialmente no cabe duda de que los servicios públicos locales han experimentado un proceso paulatino de liberalización que se ha desarrollado de forma paralela a las grandes liberalizaciones que fueron introducidas a nivel de la hoy Unión Europea. Pero este proceso no vino impuesto por la Comisión Europea. Fue más bien fruto de la ideología económica de los distintos Gobiernos que lo fueron impulsando, muy influenciados por distintos informes de los órganos estatales de defensa de la competencia (Lence Reija, 2015: 192).

\subsection{La liberalización de los servicios funerarios llevada a cabo por el Real Decreto-ley $7 / 1996$, de 7 junio, de Medidas urgentes de carácter fiscal y de fomento y liberalización de la actividad económica}

Los servicios funerarios aparecerían en la versión original de la LBRL como una competencia municipal sobre la que se podía ex artículo 25.1 crear un servicio público y también como una actividad reservada legalmente a las Entidades locales ${ }^{24}$. Sin embargo, no se incluyó entre los servicios municipales obligatorios por lo que en aquellos Municipios en los que no se hubiese configurado como un servicio público en régimen de monopolio estos servicios podían prestarse incluso por la iniciativa privada en régimen de libre competencia.

Su liberalización la llevó a cabo el primer Gobierno del Partido Popular, con el Presidente Aznar, por medio del Real Decreto-ley $7 / 1996$, de 7 junio, de Medidas urgentes de carácter fiscal y de fomento y libe-

23 Este fallo suprimió del artículo 26.2 LBRL la referencia «al Ministerio de Hacienda y Administraciones» y la previsión de que «Para reducir los costes efectivos de los servicios el mencionado Ministerio decidirá sobre la propuesta formulada que deberá contar con el informe preceptivo de la Comunidad Autónoma si es la Administración que ejerce la tutela financiera» (FJ $\left.12 .^{\circ} \mathrm{d}\right)$ ).

24 Antiguo art. 86.3 LBRL. 
ralización de la actividad económica que se aprobó dentro de un paquete más amplio de Reales Decretosleyes liberalizadores ${ }^{25}$. Como se recoge en su exposición de motivos en «materia de servicios funerarios, se liberaliza su prestación y se suprime la consideración de los servicios mortuorios como servicios esenciales reservados a las Entidades Locales». Lo que hizo el Gobierno fue asumir la recomendación que unos años antes había realizado el ya desaparecido Tribunal de Defensa de la Competencia en su importante Informe Remedios políticos que pueden favorecer la libre competencia en los servicios y atajar el daño causado por los monopolios de $1993^{26}$. Se estableció también, en su artículo 22, el régimen jurídico de las autorizaciones que con carácter reglado habilitarían para la prestación de estos servicios ahora en régimen de libre competencia. A pesar de esta liberalización se mantuvo en el artículo 25.2 j) las competencias de los Municipios sobre los Cementerios y servicios funerarios y en el artículo 26.1 a) siguieron teniendo los cementerios la consideración de servicios obligatorios para todos los Municipios (Tornos Mas, 2017: 106).

Cataluña se apresuró a regular estos servicios liberalizados por medio de la Ley 2/1997, de 3 abril, de Normas reguladoras de servicios funerarios que los calificó como un servicio esencial de interés general (Art. 1.1), previendo con la finalidad de garantizar el principio de universalidad en el acceso a los servicios funerarios la posibilidad de que como requisito previo para el otorgamiento de la autorización se pudiera exigir la constitución de una fianza o que se pudiera condicionar a que «el servicio se preste gratuitamente o de forma bonificada a las personas que, de acuerdo con las indicaciones de los servicios sociales municipales, lo requieran por falta de medios económicos propios, o en los casos en que lo acuerde la autoridad judicial ${ }^{27}$.

A pesar de la rotundidad con la que se liberalizaron los servicios funerarios no fueron pocos los Municipios que trataron de bloquear su efectividad introduciendo en sus correspondientes Ordenanzas municipales requisitos con los que en realidad trataban de impedir la concurrencia en este sector. Resulta paradigmática la sentencia del Tribunal Supremo, de 11 de mayo de $2005^{28}$, que confirmó la anulación que había acordado antes la Sala de lo contencioso-administrativo del Tribunal Superior de Justicia de Galicia de la Ordenanza del Ayuntamiento de Vigo reguladora de las actividades funerarias en el término municipal de 1997, en cuyo fundamento jurídico tercero se afirma con rotundidad que:

«No puede desconocerse al respecto, que el Real Decreto Ley 7/1996, de 7 de junio, en congruencia con la liberalización de los servicios funerarios que proclama en el artículo 22, y sin perjuicio de que los Ayuntamientos puedan someter a autorización la prestación de dichos servicios, modifica también la Ley $7 / 1985$, de 2 de abril, reguladora de las Bases del Régimen Local, para suprimir de la reserva de actividades o servicios esenciales que en favor de las Entidades locales se recogen en el artículo 86.3, la correspondiente a servicios funerarios, a lo que ha de añadirse que la referida autorización ha de tener carácter reglado, debiéndose precisar normativamente los requisitos objetivos necesarios para obtenerla y concediéndose a todos los solicitantes que reúnan los requisitos exigidos y acrediten disponer de los medios materiales necesarios para efectuar el transporte de cadáveres, preceptos que delimitan las condiciones de prestación de tales servicios y también el marco de la normativa que al respecto establezcan los Ayuntamientos, en cuanto la misma ha de respetar las condiciones de objetividad y liberalización establecidas en tales preceptos, quedando proscritas previsiones que limiten o impidan el acceso en condiciones de igualdad de las empresas al mercado liberalizado que se establece».

Para acabar con estas prácticas municipales restrictivas de la competencias, años más tarde, la Ley 24/2005, de 18 de noviembre, de Reformas para el impulso a la productividad modificó este artículo 22 para añadir que las «normas que regulen los requisitos de las autorizaciones para la prestación de estos servicios no podrán establecer exigencias que desvirtúen la liberalización del sector» y para dotar a estas autorizaciones municipales que habilitan para la prestación de servicios funerarios de eficacia en todo el territorio

25 Junto a él se aprobó el Real Decreto-ley 5/1996, de 7 de junio, de Medidas liberalizadoras en materia de suelo y de Colegios Profesionales.

${ }_{26}$ [16-8-2020] Disponible en https://www.cnmc.es/sites/default/files/1185690.pdf. En el que sostuvo en relación con estos servicios que «si los servicios mortuorios se prestan por empresas en competencia en términos más favorables para los usuarios que los que ofrece el monopolista y si no se encuentra razón convincente que justifique la constitución del monopolio, debe excluirse, desde el punto de vista de la competencia, la posibilidad, que ahora concede la Ley con carácter general a los Ayuntamientos, para que lo establezcan. Y como esta posibilidad deriva de su inclusión entre los servicios esenciales que enumera el Art. 86.3 LB, se propone excluirlos de ella» (ág. 142).

27 Art. $7.2 \mathrm{c}$ ) y d).

28 RJCAI20121607. 
nacional. En desarrollo de esta modificación legal se aprobó más tarde el Real Decreto 1225/2006, de 27 de octubre, por el que se modifica el Reglamento de la Ley de Ordenación de los Transportes Terrestres, aprobado por Real Decreto 1211/1990, de 28 de septiembre que en su artículo 139 liberalizó expresamente el transporte de cadáveres.

Lo que no hizo el Gobierno es incluir en este Real Decreto-ley 7/1996 la recomendación que también figuraba en el Informe del Tribunal de Defensa de la Competencia de establecer un régimen transitorio para las empresas que con carácter monopolístico prestaban estos servicios con anterioridad que les permitiera amortizar las inversiones que hubieran podido realizador confiando en el mantenimiento de esta situación. Lo que provocó un número importante de reclamaciones de responsabilidad patrimonial de estos antiguos prestatarios de servicios funerarios por los perjuicios sufridos debido a esta liberalización que serían más tarde rechazadas por el Tribunal Supremo ${ }^{29}$.

La posterior aprobación de la Directiva 2006/123/CE del Parlamento Europeo y del Consejo, de 12 de diciembre de 2006, relativa a los servicios en el mercado interior, que fue transpuesta a nuestro ordenamiento por medio de la Ley 17/2009, de 23 de noviembre, sobre libre acceso a las actividades de servicios y su ejercicio conocida como Ley Paraguas, plantearía la duda de si incluso podrían seguir siendo exigible estas autorizaciones, en la medida que solo se permiten estos títulos habilitantes para la prestación de servicios cuando vengan justificados por una razón imperiosa de interés general ${ }^{30}$ (Paricio Rallo, 2013 :2). En todo caso el Gobierno ha incumplido completamente el mandato recogido en la Disposición Adicional séptima de Ley 25/2009, de 22 de diciembre, de Modificación de diversas leyes para su adaptación a la Ley sobre el libre acceso a las actividades de servicios y su ejercicio, conocida como Ley Omnibus, de realizar en un plazo de seis meses un estudio y en su caso una propuesta de los cambios normativos que fueran necesarios para garantizar la libertad de elección de los prestadores de servicios funerarios y para eliminar las trabas existentes en la prestación de estos servicios.

Parece claro, sobre todo después de la aprobación de la conflictiva Ley 20/2013, de 9 de diciembre, de garantía de la unidad de mercado, que se formuló en unos términos tan expeditivos a favor de la libre competencia (Baño León, 2016: 309), que la mayoría de los servicios funerarios deben dejar de estar sometidos a una autorización municipal para someterse, si fuera preciso, a una declaración responsable o a una comunicación previa ${ }^{31}$.

Por supuesto, esta liberalización de los servicios funerarios no impide que los Municipios, por sí o de forma asociada, puedan seguir prestándolos siempre que lo hagan en régimen de libre competencia, en ejercicio de su potestad de llevar a cabo una iniciativa pública en la actividad económica. Lo que llevó al Tribunal Superior de Justicia de País Vasco, en su sentencia de 26 abril de 2010, a confirmar la anulación, declarada antes por el Juzgado de lo Contencioso-administrativo núm. 2 de San Sebastián, de la creación por parte del Ayuntamiento de esta ciudad de una empresa pública para la gestión y prestación de servicios funerarios porque de facto generaría una situación de monopolio incompatible con esta liberalización ${ }^{32}$.

Hay que tener en cuenta que esta facultad de ejercer actividades económicas por parte de Entidades locales se ha visto también considerablemente restringida por la LRSAL (García Rubio, 2015: 18 y Lence Reija, 2015: 187) ${ }^{33}$.

\subsection{La desconcertante desregulación de los mercados y los mataderos municipales efectuada por la LRSAL}

El mismo Real Decreto-Ley 7/1996, sin dar ninguna explicación en su exposición de motivos, sacó a los mataderos de los servicios que obligatoriamente tenían que prestar los Municipios con población superior a

29 Vid. SSTS de 3, 4, 11, 12, 13 y 20 abril y de 7 mayo de 2002 (RJ 200213601; RJ 200213349; RJ 2002।3464; RJ 2002।3466; RJ 200213957; RJ 2002\442427 RJ 2002\4255 y RJ 2002/4425).

30 Arts. 9.1 b) de la Directiva 2006/123/CE y 5 b) de la Ley Paraguas.

31 Art. 17.

32 RJCAl2012l607 (FJ 3. ${ }^{\circ}$.

33 Le hado dado esta nueva redacción al artículo 86.1 de la LBRL: «Las Entidades Locales podrán ejercer la iniciativa pública para el desarrollo de actividades económicas, siempre que esté garantizado el cumplimiento del objetivo de estabilidad presupuestaria y de la sostenibilidad financiera del ejercicio de sus competencias. En el expediente acreditativo de la conveniencia y oportunidad de la medida habrá de justificarse que la iniciativa no genera riesgo para la sostenibilidad financiera del conjunto de la Hacienda municipal debiendo contener un análisis del mercado, relativo a la oferta y a la demanda existente, a la rentabilidad y a los posibles efectos de la actividad local sobre la concurrencia empresarial (Art. 1. Veintitres)». 
20.000 habitantes $^{34}$, creando una situación jurídica ciertamente paradójica. Porque los mataderos dejaban de ser servicios municipales obligatorios para estos Municipios, pero se mantenía su reserva legal a favor de las Entidades locales que podían seguir teniendo mataderos si así lo acordaban, incluso en régimen de monopolio.

La segunda oleada de liberalización de servicios públicos locales, producida también durante un Gobierno del Partido Popular esta vez presidido por el Presidente Rajoy, la llevaría a cabo la polémica LRSAL que eliminó del listado de las actividades o servicios esenciales reservados legalmente a las Entidades locales precisamente a los mataderos junto con los mercados y lonjas centrales ${ }^{35}$. Además, como se hizo en 1996 con los mataderos esta Ley saca ahora a los mercados de los servicios obligatorios, en este caso para los Municipios de más de 5.000 habitantes. No obstante, mantuvo entre las competencias municipales propias, como sucedió con los servicios funerarios, las de «Ferias, abastos, mercados, lonjas y comercio ambulante» ${ }^{36}$. Lo que no hizo con los mataderos que quedaron a partir de su entrada en vigor fuera del ámbito de las competencias municipales, dando lugar a un régimen jurídico asimétrico entre los mercados y los mataderos municipales.

La situación jurídica creada con los mercados municipales no puede ser más desconcertante. Lo que explica las diferentes posiciones doctrinales que se han mantenido sobre la posibilidad de que los Municipios puedan seguir prestando estos servicios. Para González Bustos (2016: 84) las modificaciones que se han introducido en 2013 no impiden a los Municipios que puedan seguir disponiendo de mercados como un servicio público. La potestad genérica que tienen los Municipios para la creación de servicios públicos, que se recoge en el renovado artículo 25.1 de la LBRL, daría cobertura suficiente al haberse mantenido a los mercados dentro del ámbito de sus competencias ${ }^{37}$. Por el contrario, para Tornos Mas (2017: 109 y 111) después de la reforma de la LRSAL ya no es posible mantener a los mercados como un servicio público municipal. Este autor afirma que la «liberalización supone en este caso que ya no debe mantenerse un mercado municipal, pero el ente local puede seguir ordenando la venta en el dominio público, de modo que de hecho puede subsistir la imagen de la existencia del mercado municipal». En coherencia con este planteamiento (Tornos Más, 2017: 111) tampoco considera posible que se pueda llevar a cabo una remunicipalización de los mercados municipales.

«ya que la liberalización de estos servicios se ha llevado a cabo con carácter general en todo el Estado mediante ley. El legislador ha querido suprimir un servicio público existente y abrir de forma total esta actividad económica al mercado. No cabe un contrarius actus a través de una decisión local que permitiera abrir este mercado al sector público, no en ejercicio de la iniciativa pública económica en concurrencia con las empresas privadas, lo que sí es posible, sino a través de la prestación de un servicio público con las ventajas que ello supone (actuar fuera del mercado, con un régimen jurídico especial y con fondos públicos). Un ente local no puede hoy prestar los servicios funerarios como servicio público. Tan sólo el legislador estatal podría remunicipalizar de nuevo este servicio, y lo mismo cabe decir de los mercados municipales».

Esta equiparación entre la liberalización de los servicios funerarios y los mercados no parece adecuada. En 1996 la despublicatio de los servicios funerarios vino acompañada de una nueva regulación de esta actividad abierta a la libre competencia que la sometía a un régimen de autorización municipal. Con los mercados, la LRSAL sólo se ha ocupado de eliminar la reserva de la actividad en favor de las Entidades locales y su anterior condición de servicio obligatorio sin introducir ninguna nueva regulación. Probablemente esta ausencia sea debida a la propia actividad de los mercados que por su naturaleza difícilmente va a ser asumida por la iniciativa privada.

Ahora bien, esta circunstancia tampoco puede justificar, sin más, que se puedan crear nuevos mercados municipales como servicios públicos sin que se cumplan los requisitos establecidos en los apartados 3 a 4

34 Art. 24.

35 La supresión de los mercados del listado de las actividades reservadas a las Entidades locales tiene también su origen en un informe de la desaparecida Comisión Nacional de la Competencia, titulado Informe sobre la competencia en el servicio de mercados centrales mayoristas de abastecimiento de productos alimentarios perecederos en destino de 2013. [20-8-2020] Disponible en: https:// www.cnmc.es/sites/default/files/1187747_7.pdf.

36 Actual art. 25.2 i) LBRL.

37 Esta posición coincide con la Nota emitida por la Federación Española de Municipios y Provincias sobre Competencia municipal sobre los mercados de abastos tras la entrada en vigor de la Ley 27/2013, de 27 de diciembre, de racionalización y sostenibilidad de la Administración Local (LRSAL). [20-8-2020] Disponible en: https://www.fempclm.es/Ley-Racionalizacion-y-Sostenibilidad-de-laAdministracion-local_es_0_919.html. 
del nuevo artículo 25 de la LBRL que exigen la necesidad de la aprobación de una Ley específica que entre, otros aspectos, prevea «la dotación de los recursos necesarios para asegurar la suficiencia financiera de las Entidades Locales sin que ello pueda conllevar, en ningún caso, un mayor gasto de las Administraciones Públicas».

La clave, a mi juicio, se encuentra en diferenciar entre los mercados municipales que estuviesen en servicio en el momento de la entrada en vigor de la LRSAL y los que se quieran crear con posterioridad. Ante la falta de previsión de un régimen transitorio aplicable a los mercados preexistentes se debe interpretar que las exigencias del artículo 25 de la LBRL no se pueden aplicar con carácter retroactivo. En consecuencia, podrán seguir funcionando como servicios públicos municipales siempre que la Entidad local cumpla estrictamente con los principios de estabilidad presupuestaria y sostenibilidad financiera. Sólo en caso de que incurran en déficit presupuestario se tendrán que plantear, entre otras posibles medidas, la supresión de esta actividad hasta recuperar el equilibrio presupuestario. Consecuentemente y con estas mismas condiciones un Municipio podrá acordar también la remunicipalización o más propiamente la reinternalización (Alemany Garcías, 2020: 26) de un mercado que se hubiese estado gestionando indirectamente antes de la LRSAL por la iniciativa privada.

La supervivencia de los mataderos municipales ha quedado mucho más comprometida tras esta Ley ya que se excluyó esta materia a radice de las competencias municipales. Los Municipios, por lo tanto, no pueden seguir prestando la actividad de matadero bajo la faz del servicio público, con las ventajas que ello le supone de no tener que ajustarse a las normas sobre libre competencia. Todo ello sin perjuicio de que puedan seguir ejercitando esta actividad económica en las mismas condiciones de competencia que la iniciativa privada.

Otra opción posible sería la de que por medio de una disposición legal, que previsiblemente tendría origen autonómico, se tomara la decisión de «resucitar» a los mataderos como una actividad esencial reservada a las Entidades locales. Como ha hecho precisamente Islas Baleares mediante su Decreto-ley 1/2018, de 19 de enero, de medidas urgentes para la mejora y/o la ampliación de la red de equipamientos públicos de usos educativos, sanitarios o sociales de la Comunidad Autónoma de las Islas Baleares que en su Disposición Final segunda ha declarado expresamente el servicio de matadero como un servicio de interés económico general a favor de determinados Municipios baleares ${ }^{38}$. En su exposición de motivos se justifica esta reserva porque la «eliminación de esta reserva de actividad de matadero ha supuesto una merma en los instrumentos jurídicos para tutelar con más eficacia esta actividad, teniendo en cuenta las implicaciones higiénico-sanitarias y las repercusiones que tiene directamente sobre el sector ganadero de las Islas; por ello se decide recuperar esta competencia y volver a considerarla un servicio público. Asimismo, se considera necesario calificarla como servicio de interés económico general para que pueda tener mejor acceso a las ayudas y compensaciones que necesita esta actividad» ${ }^{39}$.

El margen que queda para futuras liberalizaciones de servicios públicos económicos locales es ya más reducido. Las tres únicas actividades que siguen estando en la LBRL reservadas a las Entidades locales, abastecimiento domiciliario y depuración de aguas, recogida, tratamiento y aprovechamiento de residuos, y transporte público de viajeros tienen una larga tradición como servicio público. Además, se enfrentan al hándicap de que suelen ser actividades deficitarias para las Haciendas locales. En el mencionado Informe del antiguo Tribunal de Defensa de la Competencia de 1993 se abordó la eventual liberalización de los transportes urbanos colectivos pero se descartó, recomendado en su lugar la diversificación en más de una concesión, cuando fuera factible, la explotación de las líneas y la limitación a un máximo de 10 años de su duración ${ }^{40}$

Por otra parte, hay que destacar que el Derecho de la Unión Europea hasta el momento no ha obligado a liberalizar estas actividades que están formalmente reservadas a las Entidades locales y que, por lo tanto, pueden seguir prestando mediante la figura de los servicios públicos locales que pueden actuar incluso en régimen de monopolio (Ortega Bernardo, 2006: 95).

38 En concreto, Formentera, Eivissa, Santa Eulària des Riu, Sant Josep de sa Talaia, Sant Antoni de Portmany, Sant Joan de Labritja, Maó, Ciutadella, Manacor, Felanitx, Inca y Palma.

39 La extraordinaria y urgente necesidad para que la declaración se haga por Decreto-ley vendría debido «a causa de la grave crisis que está afectando a la actividad de matadero, tanto por las dificultades económicas de su mantenimiento como por la situación de las instalaciones, algunas de ellas en un lamentable estado higiénico-sanitario. Estas circunstancias pueden suponer un riesgo inminente de cierre de las instalaciones que podría afectar muy negativamente a la comercialización de carnes frescas a nuestros consumidores y suponer graves perjuicios a nuestro sector ganadero».

40 Pág. 147 del Informe. 


\section{LA DISCUTIBLE CONCURRENCIA DE SERVICIOS PÚBLICOS MUNICIPALES CON LA INICIATIVA PRIVADA}

No es infrecuente que los servicios públicos se presten en régimen de concurrencia, que no de libre competencia, con la iniciativa privada. Así sucede, por ejemplo, en el ámbito de la educación, la asistencia sanitaria y los servicios sociales. Se trata de servicios públicos que no tienen carácter económico y que se corresponden con derechos que están constitucionalizados como el derecho a la educación (Art. $27 \mathrm{CE}$ ), a la salud (Art. $43 \mathrm{CE}$ ) o el derecho al acceso a los servicios sociales (Art. $50 \mathrm{CE}$ ) y que han dado lugar a los respectivos sistemas públicos educativos, sanitarios y de servicios sociales. Nuestro ordenamiento jurídico considera que las prestaciones educativas, sanitarias y de servicios sociales privadas complementan a las propias del servicio público.

En el ámbito local los servicios públicos tampoco tienen porqué desenvolverse en una situación de monopolio, aunque sea cierto que, debido a que a veces constituyen una suerte de monopolio natural como sucede con el abastecimiento de agua o porque resultan deficitarios como la recogida y el tratamiento de residuos o el transporte urbano de viajeros, suelen prestarse sin concurrencia con la iniciativa privada.

\subsection{La aplicación de las normas sobre competencia a los servicios públicos locales}

Durante mucho tiempo se ha discutido si las normas sobre competencia podrían ser aplicadas también a las Administraciones Públicas, siendo mucho más controvertida aún su aplicación en el ámbito de los servicios públicos que por su propia naturaleza suponen una restricción clara a la libre competencia (Malaret, 2003: 577). Precisamente en 1999 las Cortes Generales modificaron el artículo 2 de la Ley 16/1989, de 17 de julio, de Defensa de la Competencia ${ }^{41}$ para distinguir claramente, sin perjuicio de la eventual aplicación del Derecho de la Unión Europea, entre conductas -entre las que cabría incluir a las actuaciones administrativas- que estarían excluidas de la aplicación de las normas sobre competencia por tratarse de «acuerdos, decisiones, recomendaciones y prácticas que resulten de la aplicación de una ley» y aquellas «situaciones de restricción de competencia que se deriven del ejercicio de otras potestades administrativas o sean causadas por la actuación de los poderes públicos o las empresas públicas sin dicho amparo legal», previsiones que actualmente se encuentran recogidas en los apartados 1 y 2 del también artículo 2 de la vigente Ley 15/2007, de 3 julio, que regula la Defensa de la Competencia.

De acuerdo con estos preceptos, como ha destacado claramente la doctrina administrativa (Canedo Arrillaga, 2014: 157) y ha reconocido el propio Tribunal Supremo ${ }^{42}$, no todas las actuaciones administrativas están excluidas de por sí de la aplicación de las normas sobre competencia. La clave radica en determinar si la actuación constituye una aplicación de una norma con rango de ley.

Si trasladamos esta regulación al ámbito de los servicios públicos locales la conclusión a la que se puede llegar, como ha apuntado Ortega Bernardo (2006: 87), es que la:

«caracterización de una actividad como servicio público local puede servir, y de ahí la utilidad de la declaración, para que, incluso en los casos en los que la actividad municipal sea prestada en concurrencia con los particulares -lo que ocurrirá en todos los supuestos de actividades no reservadas expresamente por ley e incluso con respecto a las declaradas reservadas legalmente, en aquellos casos en los que el monopolio que autoriza la ley, por ejemplo el artículo 86.3 LRBRL, no se hubiera efectivamente implantado-, se trate de una actividad en la que la presencia del interés general exonera del estricto cumplimiento de las reglas de la competencia».

Pero hay que tener en cuenta que las restricciones que se introduzcan a la libre competencia tienen que venir justificadas por razones de interés general y que de conformidad con lo que dispone el ya citado artículo 106.2 del TFUE deben estar dirigidas a que se pueda cumplir con la misión específica que tenga asignado el concreto servicio público. En esta línea los propios órganos de defensa de la competencia están apostando por realizar un enjuiciamiento mínimo de la actividad administrativa para determinar si esta actividad encierra en realidad una práctica anticompetitiva de la Administración (González Toroba, 2009: 166-170).

41 Ley 52/1999, de 28 de diciembre, de reforma de la Ley 16/1989, de 17 de julio, de Defensa de la Competencia.

42 STS de 18 de julio de 2016 (RJ 2016/4367). 
Es más, como ha apuntado Rebollo Puig (2019: 170) se puede plantear por parte de los empresarios o las empresas perjudicadas por las prácticas anticompetitivas de la Administración el ejercicio de acciones ante la jurisdicción civil por competencia desleal al amparo de lo dispuesto en el artículo 15.2 de la Ley 3/1991, de 10 de enero, de Competencia desleal ${ }^{43}$.

«en tanto que su posibilidad de desplazar las reglas de la competencia -y, en especial, su financiación pública- solo es admisible en la medida necesaria para que cumplan la misión específica que tengan confiada (art. 106.2 TFUE). Lo que sobrepase esa medida necesaria es ilegítimo y, por tanto, vulnerador de normas reguladoras de la concurrencia».

Atendiendo a estos planteamientos no parece acertada (Lence Reija, 2015: 192) la doctrina establecida por el Tribunal Superior de Justicia de Galicia en la sentencia de su Sala de lo contencioso-administrativo, de 29 febrero de $2012^{44}$, que desestimó el recurso que habían interpuesto unas entidades que se dedicaban a la impartición de cursos de inglés contra el acuerdo del Tribunal Galego de Defensa da Competencia (TGDC) de no incoar un expediente sancionador contra el Ayuntamiento de Ferrol por realizar presuntas prácticas restrictivas de la competencia por ofrecer cursos de inglés a niños de la población con carácter gratuito atendiendo únicamente al nivel de inglés de los alumnos. En su extenso fundamento jurídico tercero se señala, sin efectuar el más mínimo enjuiciamiento de los efectos que los cursos tienen sobre la competencia, que:

«..., si bien la educativa no es una competencia básica del municipio, se enmarca en un campo en el que la legislación abre a los Ayuntamientos opciones para implicarse en ella a fin de mejorar la calidad de la formación, que en este caso se lleva a cabo programando y desarrollando programas educativos dirigidos a los centros escolares del municipio».

A continuación, descarta que esta oferta de cursos de inglés constituya una práctica de competencia desleal ya que:

«... no se aprecia finalidad concurrencial en la actuación del Concello, puesto que su objetivo no es la captación de clientes para obtener un beneficio económico ni la intervención en un mercado competitivo en concurrencia con otros operadores, sino lograr un fin de interés general, cual promover el aprendizaje de la lengua inglesa entre escolares del municipio de Ferrol con el fin de mejorar su formación en ese aspecto. Y mucho menos cabe tachar su actuar de desleal, por el empleo de maniobras, maquinaciones, formas o medios que la conciencia social reprueba como contrarios a la moral comercial. Tampoco se puede afirmar que el Concello de Ferrol haya obtenido una ventaja competitiva, pues ni siquiera tenía el objetivo de entrar en competencia con nadie» (FJ $\left.3 .^{\circ}\right)$.

Finalmente, hay que destacar que las normas sobre competencia también se pueden aplicar a los servicios públicos que se prestan en régimen de monopolio. Especialmente interesante es la sentencia del Tribunal Supremo, de 31 enero $2001^{45}$, que, revocando la sentencia de instancia, declaró la invalidez de un precepto de la Ordenanza del Ayuntamiento de Sevilla reguladora de los Mercados de Abastos que prohibía la instalación de establecimientos que se dedicaran a la venta de alimentos en una distancia inferior a la de 200 metros de distancia del mercado por suponer una vulneración de la libertad de empresa consagrada en el artículo 38 de la Constitución.

\subsection{El caso paradigmático de las instalaciones deportivas de uso público}

La LBRL supuso un importante impulso a la implantación de infraestructuras deportivas en nuestro país (Jiménez Soto, 2015: 5) que en los años ochenta del siglo pasado eran prácticamente inexistentes. Su artículo $25.2 \mathrm{~m}$ ) le atribuyó a los Municipios competencias sobre «Actividades o instalaciones culturales y

43 Este precepto establece que «Tendrá también la consideración de desleal la simple infracción de normas jurídicas que tengan por objeto la regulación de la actividad concurrencial». Por otra parte, de acuerdo con lo que se prevé en el artículo 3.1 de la Ley de Competencia desleal su régimen se aplica «a los empresarios, profesionales y a cualesquiera otras personas físicas o jurídicas que participen en el mercado».

44 JUR\2012\104636.

$45 \mathrm{RJ} 2001 \backslash 1726$. 
deportivas: ocupación del tiempo libre; turismo» ${ }^{46} \mathrm{y}$, como se ha señalado ya, las instalaciones deportivas de uso público figuraban, y siguen figurando en la actualidad, entre los servicios municipales obligatorios de los Municipios con población superior a los 20.000 habitantes $^{47}$. Lo que no hizo esta Ley es reservar esta actividad a las entidades locales, probablemente porque consideraba juiciosamente que no se debía impedir a la iniciativa privada la construcción y explotación de esta clase de instalaciones.

Debido a este mandato legal, y gracias también a la legislación autonómica y a las políticas públicas que en materia de deporte han puesto en marcha durante las últimas décadas las Comunidades Autónomas, hoy existe un razonable equipamiento deportivo en la gran mayoría de las localidades españolas.

La cuestión que se plantea en la actualidad, que ha dado lugar a una elevada conflictividad tanto en la vía civil como en la contencioso-administrativa y ante los órganos de defensa de la competencia de lo que se ha hecho eco la doctrina (Gonzalez Torroba, 2017: 169-175 y Ortega Bernardo 2006: 88-94), es si sigue teniendo sentido que las instalaciones deportivas de uso público puedan mantener la consideración de servicios públicos municipales de forma que puedan disfrutar de un régimen más beneficioso que incluya, entre otros aspectos, una financiación pública adicional también en aquellos entornos, sobre todo urbanos, en los que esta actividad puede ser asumida por la iniciativa privada en régimen de libre competencia.

Hasta el momento la jurisprudencia no ha puesto en cuestión esta situación. Puede citarse, por ejemplo, la sentencia del Tribunal Supremo, de 20 junio de $2006^{48}$, que confirmó la anterior del Tribunal Superior de Justicia de Valencia ${ }^{49}$, en la que se rechazó el planteamiento, que en las dos instancias se había solicitado, de una cuestión prejudicial al Tribunal de Justicia de la Unión Europea para que determinase si esta actividad pudiera tener una incidencia comunitaria y que, por lo tanto, le pudiera resultar de aplicación lo dispuesto en el artículo 106.2 del TFUE. Se afirma en el fundamento jurídico $7 .^{\circ}$, a mi modo de ver, de una forma un tanto simplista que:

«Es obvio que esa actividad prestacional de la Administración local en este supuesto no percute en el mercado único de la Unión, y no se refieren a situaciones como esas los preceptos del Tratado que se dicen vulnerados. Pero es que es perfectamente compatible esa actividad de la Corporación facilitando a quienes lo deseen la práctica de actividades como el aeróbic o el fitnees e incluso el acondicionamiento físico de adultos y la puesta a disposición del público de aparatos de tonificación, musculación y trabajo cardiovascular con la que en ese mismo ámbito puedan prestar las empresas constituidas por la iniciativa privada, porque los medios y la atención pueden ser distintos y prestados de modo diferente, y dirigidos a sectores de población con necesidades y conveniencias diversas, por lo que una y otra forma de prestar la misma actividad no empece la existencia de ambas». (FJ $\left.7 .^{\circ}\right)$.

Nuestro Alto Tribunal no solo pasa por alto la jurisprudencia ALTMARK, de la que se razonablemente se puede derivar que no se pueda descartar a priori que el mantenimiento de estas instalaciones deportivas como servicios públicos municipales pueda suponer una barrera de entrada a empresas de otros países miembros que se dedican a esta misma actividad a gran escala, es que ni siquiera se detiene en valorar si en el asunto a quo había una justificación suficiente del interés público que justificara las restricciones impuestas a la libre competencia en este sector.

Resulta evidente que para garantizar el acceso sin discriminación a este tipo de instalaciones con carácter general a toda la población, incluso en los centros urbanos, sigue siendo necesario que se puedan excluir su prestación de una aplicación estricta de las normas sobre competencia. Pero allí donde existe un mercado suficiente para este tipo de instalaciones deportivas el Municipio tendría que operar, si es que tiene esa intención, en régimen de libre competencia en las mismas condiciones que cualquier otro empresario del sector con las únicas excepciones que se deriven de las exigencias de interés públicos que se especifiquen al configurar la prestación (Vgr. Bonificación a determinados colectivos). Lo cierto es que la LRSAL en relación con las instalaciones deportivas no ha introducido ninguna modificación (Jiménez Soto, 2015: 14) por lo que ha tenido una escasa incidencia en esta situación, más allá de la exigencia del cumplimiento del equilibrio presupuestario.

\footnotetext{
46 Actual letra I), "Promoción del deporte e instalaciones deportivas y de ocupación del tiempo libre”, del artículo 25.2 LBRL.

47 Art. $26.1 \mathrm{c})$ LBRL.

48 RJI2006/8317. Doctrina que reitera en la posterior STS de 29 de junio de 2009 (RJI2009\4424).

49 Sentencia de 23 mayo de 2003 (JT\2004\37).
} 


\section{LIBRE CONCURRENCIA EN EL ACCESO A LA GESTIÓN INDIRECTA DE LOS SERVICIOS PÚBLICOS LOCALES COMO MEDIO PARA FAVORECER LA LIBRE COMPETENCIA}

Existe, por último, un ámbito de los servicios públicos locales en el que se ha experimentado un importante avance por lo que se refiere a la participación de la iniciativa privada en su prestación, el que se refiere a su gestión indirecta a través de la contratación pública. Y ello con independencia de que la actividad declarada como servicio público local se preste en régimen de monopolio o en concurrencia con los particulares.

Tradicionalmente se venía defendiendo que los Municipios tenían discrecionalidad a la hora de decidir si gestionaban un servicio público de su titularidad directamente por medio de su propia organización o lo hacían de forma mediata a través de terceros. Sobre esta cuestión también ha incidido la LRSAL que le dio una nueva regulación a las formas de gestión de los servicios públicos que se recoge en el actual artículo 85.2 de la LBRL. En coherencia con la finalidad última de la reforma legal, de velar por la sostenibilidad financiera las Entidades locales, se establece ahora que los «servicios públicos de competencia local habrán de gestionarse de la forma más sostenible y eficiente» para pasar a hacer la distinción clásica entre gestión directa (por la propia Entidad Local o a través de un Organismo autónomo local, de una Entidad pública empresarial local o de una Sociedad mercantil local, cuyo capital social sea de titularidad pública) o indirecta que se haría mediante el actual contrato de concesión de servicios regulado hoy en la Ley 9/2017, de 9 de noviembre, de Contratos del Sector público, por la que se transponen al ordenamiento jurídico español las Directivas del Parlamento Europeo y del Consejo 2014/23/UE y 2014/24/UE, de 26 de febrero de 2014 (en adelante LCSP) ${ }^{50}$.

Además, se añaden una serie de exigencias formales para la prestación de los servicios públicos de forma directa cuando no se utilizan los medios propios del Municipio en los artículos 85 bis y ter lo que ha llevado a algún sector de la doctrina a defender que hay una preferencia de la LBRL por la gestión indirecta de los servicios públicos (Esteve Pardo, 2017: 331) mientras que para otra parte de la doctrina (García Rubio, 2015: 12) la preferencia sería para su gestión directa. En todo caso, lo que parece claro es que en la actualidad los Municipios han perdido la discrecionalidad de la que disfrutaban antes a la hora de elegir las formas de gestión de sus servicios público. Sus decisiones tendrán que ajustarse -y por lo tanto motivarse en la correspondiente memoria- al concepto jurídico indeterminado que supone una gestión más sostenible y eficiente de los servicios públicos (Alemany Garcia, 2020: 5). Su interpretación y aplicación se ha visto ciertamente complicada con la novedad que se ha introducido en el artículo 30.3 de la nueva LCSP que establece con bastante rotundidad que la «prestación de servicios se realizará normalmente por la propia Administración por sus propios medios. No obstante, cuando carezca de medios suficientes, previa la debida justificación en el expediente, se podrá contratar de conformidad con lo establecido en el Capítulo $V$ del Título II del Libro II de la presente Ley» que es precisamente el capítulo en el que se regula el contrato de concesión de servicios. Ni en la LBRL ni en la nueva LCSP ${ }^{51}$ se contempla al contrato de servicios como una modalidad de gestión indirecta de los servicios públicos probablemente porque no se le traslada al contratista el riesgo operacional de la actividad. Así se refleja con claridad en la letra a) del artículo 312 de la LCSP que prevé que, cuando el contrato conlleve prestaciones directas a favor de los ciudadanos, antes «de proceder a la contratación de un servicio de esta naturaleza deberá haberse establecido su régimen jurídico, que declare expresamente que la actividad de que se trata queda asumida por la Administración respectiva como propia de la misma, determine el alcance de las prestaciones en favor de los administrados, y regule los aspectos de carácter jurídico, económico y administrativo relativos a la prestación del servicio».

50 En relación con la gestión indirecta la LBRL se limita a señalar que se hará «mediante las distintas formas previstas para el contrato de gestión de servicios públicos en el texto refundido de la Ley de Contratos del Sector Público, aprobado por Real Decreto Legislativo 3/2011, de 14 de noviembre». Se trata de una remisión que se encuentra desfasada. No sólo porque esta disposición ha sido ya derogada por la LCSP de 2017, sino sobre todo porque como consecuencia de la transposición del paquete de Directivas de 2014 se ha suprimido el contrato de gestión de servicio público. Esta modalidad contractual se reconduce ahora a las figuras de los contratos de concesión de servicios o de servicios en función de que haya o no una efectiva transferencia del riesgo de explotación al contratista, respectivamente. En el contrato de concesión de servicios el concesionario asume, a su riesgo y ventura, la organización y prestación del servicio público, durante el plazo establecido y con estricta sujeción a lo establecido en el contrato.

$51 \mathrm{El}$ art. 284.1 de la LCSP establece expresamente que «La Administración podrá gestionar indirectamente, mediante contrato de concesión de servicios, los servicios de su titularidad o competencia siempre que sean susceptibles de explotación económica por particulares. En ningún caso podrán prestarse mediante concesión de servicios los que impliquen ejercicio de la autoridad inherente a los poderes públicos». 
Con independencia del tipo de contrato administrativo que elija el Municipio para dejar en manos de la iniciativa privada la efectiva prestación del servicio público a los ciudadanos es importante destacar el papel central que juega la garantía de la libre concurrencia en el acceso a estas contrataciones (Espinosa García, 2011). Esta concurrencia permite trasladar a la prestación del servicio público ventajas tanto en relación con su eficiencia como con sus costes. Se debe velar porque la libre concurrencia se respete en todas las fases del procedimiento de contratación pública (Requisitos de solvencia, criterios de adjudicación y condiciones especiales de ejecución) para lo que los pliegos de cláusulas administrativas y de prescripciones técnicas resultan absolutamente determinantes (Ibáñez García, 2010: 2).

En esta función de control de la conformidad de la contratación pública con la libre competencia juegan un papel cada vez más importancia los órganos de defensa de la competencia, tanto la actual Comisión Nacional de los Mercados y de la Competencia ${ }^{52}$ como los autonómicos ${ }^{53}$ (Canedo Arrillaga, 2014: 156 y Martín Bautista, 2016b: 35). La Comisión Nacional de los Mercados y la Competencia está además legitimadas para recurrir aquellas actuaciones administrativas que puedan suponer una restricción a la libre competencia ${ }^{54}$. De acuerdo con lo que dispone el artículo 132.3 de la LCSP, los órganos de contratación, la Junta Consultiva de Contratación Pública del Estado o sus homólogos autonómicos y los órganos competentes para resolver el recurso especial en materia de contratación están obligados a notificar a la Comisión Nacional de los Mercados y la Competencia o a las autoridades autonómicas de competencia según los casos «cualesquiera hechos de los que tengan conocimiento en el ejercicio de sus funciones que puedan constituir infracción a la legislación de defensa de la competencia».

De la relevancia que la libre concurrencia en la contratación pública tiene para los servicios públicos es una buena prueba el curioso asunto resuelto por la sentencia del Tribunal Superior de Justicia de Andalucía (Sala de Sevilla), de 24 de mayo de 201755. El Pleno del Ayuntamiento de Sevilla aprobó en 2014 una nueva Ordenanza Municipal de Limpieza Pública y Gestión de Residuos Municipales en la que se decidió, al amparo de lo dispuesto en la Ley 22/2011, de 28 de julio, de residuos y suelos contaminados ${ }^{56}$ y del Decreto 73/2012, de 20 de marzo, que aprueba el Reglamento de Residuos de Andalucía ${ }^{57}$, cambiar el régimen de la gestión de los aceites usados en la restauración. Anteriormente cada productor se ocupaba de la gestión de estos residuos que podía contratar con terceros en régimen de libre competencia. Esta Ordenanza municipal creó un sistema de gestión integrada de los aceites usados procedentes de cocina al que obligatoriamente se tenían que incorporar todos los productores de estos residuos. Para la gestión de este sistema de gestión integrado con el que se iba a monopolizar en la ciudad Sevilla la gestión de los aceites usados se convocó una licitación que fue adjudicada a la entidad Biouniversal S. L.

La reacción de las entidades gestoras de aceites usados, que se ejerció a través de la Asociación Nacional de Gestores de Residuos de Aceites y Grasas Comestibles (GEREGRAS), no se hizo esperar. Esta Asociación recurrió, en primer lugar, los Pliegos de Condiciones Técnicas y Administrativas de la contratación del Servicio de Recogida selectiva de aceites vegetales usados municipales, domésticos, no peligrosos que habían sido aprobados antes de la aprobación de la Ordenanza Municipal. Aunque inicialmente su impugnación llevada a cabo a través del recurso especial en materia de contratación fue desestimada ${ }^{58}$, el Tribunal Superior de Justicia acabaría anulando ${ }^{59}$ la adscripción obligatoria a este sistema de gestión integrada por falta de motivación. ya que no se había justificado en el expediente de contratación la mayor eficiencia y eficacia del nuevo sistema.

52 Para facilitar a las entidades del sector público la elaboración de sus pliegos de forma respetuosa con la libre competencia la extinta Comisión Nacional de la Competencia aprobó en 2011 la Guía sobre Contratación Pública y Competencia. [20-8-2020] Disponible en: https://www.competencia.euskadi.eus/contenidos/informacion/guias_gidak/es_guias/adjuntos/GUIA_CONTRATACION_COMPETENCIA es.pdf.

53 Múy reciente es la Guía sobre Contratación Pública y Competencia. Ley 9/2017, de 8 de noviembre, de Contratos del sector público, elaborada en 2018 por la Autoridad Vasca de la Competencia. [20-8-2020] Disponible en: https://www.competencia.euskadi. eus/contenidos/informacion/guias_gidak/es_guias/adjuntos/GUIA_CONTRATACION_COMPETENCIA_es.pdf.

54 El art. 5.4 de la Ley $3 / 2013$, de 4 junio, de creación de la Comisión Nacional de los Mercados y la Competencia establece que «En cumplimiento de sus funciones, la Comisión Nacional de los Mercados y la Competencia está legitimada para impugnar ante la jurisdicción competente los actos de las Administraciones Públicas sujetos al Derecho administrativo y disposiciones generales de rango inferior a la ley de los que se deriven obstáculos al mantenimiento de una competencia efectiva en los mercados».

55 JURI2017\237315

56 Art. 12.5.c).

57 Art. 9.

58 Por medio de la Resolución del Tribunal de Recursos Contractuales del Ayuntamiento de Sevilla, Resolución 17/2013, de 12 de septiembre de 2013. [20-8-2020] Disponible en: https://www.sevilla.org/servicios/contratacion/tarcas/resoluciones/2013/resolucion-17-2013.pdf.

59 STSJ de Andalucía de 30 de junio de 2015 (JUR 2015\196019). 
Simultáneamente se presentó una denuncia ante la Agencia de Defensa de la Competencia de Andalucía contra LIPASAM, entidad mercantil de titularidad integra municipal que presta los servicios de limpieza pública y recogida y tratamiento de residuos en Sevilla, en relación con el procedimiento de licitación y posterior adjudicación del contrato del servicio de recogida selectiva de aceites usados municipales, domésticos, no peligrosos basándose en que esta actuación anulaba la competencia en el acceso a la gestión de los aceites usados de cocina al monopolizar esta actividad en la empresa adjudicataria del contrato de servicios. El Consejo de Defensa de la Competencia de Andalucía, por medio de su Resolución, de 21 de diciembre de 2015, acordó después de realizar la correspondiente investigación la no incoación del procedimiento sancionador y el correspondiente archivo de la denuncia porque consideró que los hechos denunciados no presentaban indicios racionales de infracción de la Ley de Defensa de la Competencia, decisión que constituye el objeto del recurso contencioso-administrativo resuelto por esta sentencia.

Para el Tribunal Superior de Justicia de Andalucía, que desestima el recurso, no se produjo abuso de posición dominante porque no se había acreditado la existencia de un mercado apreciable de recogida de aceite y además no se había impedido a ninguna empresa participar en la licitación. Considera que LIPASAM está ejercitando, como ente instrumental del Ayuntamiento de Sevilla, sus competencias en materia de gestión de residuos y que, por lo tanto, no actúa como una operadora en el mercado de esta clase de estos residuos. Descarta la existencia de una situación de competencia desleal afirmando categóricamente, en su fundamento jurídico séptimo, que:

«...como ya expresó la resolución de la CDC no existen indicios de infracción de leyes, pero además dicha infracción debe llevar a la obtención de una ventaja competitiva, y como se dijo, Lipasam no compite en el mercado de la recogida de aceite por lo que no puede obtener ventajas competitivas. Tampoco se falsea la libre competencia ya que existió una licitación pública a la que pudo concurrir cualquier empresa autorizada».

Finalmente, hay que destacar que progresivamente se han ido reduciendo también las posibles restricciones que a la libre concurrencia en la contratación pública se producía por la utilización de convenios administrativos o de fórmulas in house (Fernández García, 2013: 97 y Martín Bautista, 2016a: 39). La Ley 40/2015, de 1 de octubre, de Régimen jurídico del sector público estableció por primera vez una regulación general de los convenios administrativos ${ }^{60}$ y en su artículo 47.1 in fine se dispone que los «convenios no podrán tener por objeto prestaciones propias de los contratos. En tal caso, su naturaleza y régimen jurídico se ajustará a lo previsto en la legislación de contratos del sector público», para lo que obliga a que en su memoria justificativa se analice el carácter no contractual de la actividad que se va a desarrollar ${ }^{61}$. De acuerdo con este planteamiento, por poner un ejemplo, el Tribunal Supremo en su sentencia, de 27 de abril de $2006^{62}$, confirmó la anulación que había efectuado en primera instancia el Tribunal Superior de Justicia de Valencia de la asignación mediante un convenio interadministrativo de la prestación del servicio de agua potable y alcantarillado de varios Ayuntamientos valencianos a una empresa mixta participada mayoritariamente por un Municipio distinto que se había realizado sin ninguna licitación pública.

Igualmente se ha producido una importante acotación del alcance de la denominada contratación directa o in house providing, sobre todo a partir de la jurisprudencia del Tribunal de Justicia de la Unión Europea ${ }^{63}$, que actualmente se encuentra regulada en nuestro ordenamiento jurídico en el artículo 86 de la citada Ley de Régimen jurídico del sector público y en los artículos 32 y 33 de la LCSP.

\footnotetext{
60 Capítulo IV de su Título Preliminar (Arts. 47 a 53).

61 Artículo 50.1 LRJSP

62 RJ $2006 \backslash 4675$.
}

63 Merece destacarse, por su relevancia para el ámbito local, la sentencia de este Tribunal, de 29 de noviembre de 2012 , recaída en el Caso Econord SpA (TJCEl20121365) en la que se precisan las condiciones de control que tienen que ejercer los Municipios que se integran en el ente instrumental de otro Municipio para encomendarle la gestión de un servicio público, como es el de la recogida de basuras, para que no constituya un incumplimiento de la normativa de contratación pública señalando que «cuando varias administraciones públicas, en su condición de entidades adjudicadoras, crean en común una entidad encargada de realizar la misión de servicio público que incumbe a aquéllas o cuando una administración pública se adhiere a la mencionada entidad, el requisito sentado por la jurisprudencia del Tribunal de Justicia -según el cual, para que tales administraciones públicas queden dispensadas de la obligación de tramitar un procedimiento de adjudicación de contratos públicos de conformidad con las normas del Derecho de la Unión, han de ejercer conjuntamente sobre dicha entidad un control análogo al que ejercen sobre sus propios servicios- se considerará cumplido cuando cada una de las administraciones públicas participe tanto en el capital como en los órganos de dirección de la entidad en cuestión» (parágrafo $33 .^{\circ}$ ). 


\section{CONCLUSIONES}

En una economía de mercado como la española integrada dentro del mercado común que representa la Unión Europea los servicios públicos de carácter económico siguen teniendo su razón de ser porque garantizan el acceso a determinadas prestaciones por parte de todos los ciudadanos en condiciones de igualdad. Esta función es especialmente relevante en el ámbito local donde hay una gran heterogeneidad de Municipios.

La onda liberalizadora de las últimas décadas, que ha alcanzado a muchos de los tradicionales servicios económicos, ha tenido un menor impacto sobre los servicios públicos locales debido a su carácter deficitario (transporte urbano, recogida de basuras) y a que en ocasiones constituye un monopolio natural (abastecimiento de aguas y recogida de aguas residuales). No obstante, hay que tener en cuenta que las restricciones que se impongan a las normas de la competencia como consecuencia del establecimiento de un servicio público deben estar justificado por las misiones específicas a las que atiende ex artículo 106.2 del TFUE. Además, de acuerdo con la jurisprudencia ALTMARK, el ámbito más o menos restringido que pueden tener los servicios públicos locales no es un obstáculo para que las restricciones puedan tener incidencia a nivel de la Unión Europa.

Allí donde las actividades antes reservadas a las Entidades locales por la LBRL se hayan liberalizado por completo, como ha pasado con los servicios funerarios y con los mataderos municipales y, de una forma menos intensa, con los mercados, los servicios públicos ya no tienen cabida. El único papel que pueden desempeñar los Municipios es el de ejercer una actividad económica en estos sectores en régimen de libre competencia, aunque sometida a las nuevas exigencias que ha introducido la LRSAL.

Si el servicio público local concurre con la iniciativa privada se debe velar porque la incidencia en la libre competencia sea la imprescindible para que el servicio público cumpla con sus fines.

La libre concurrencia en el acceso a los contratos públicos relacionados con la gestión indirecta de los servicios público constituye una pieza clave, y cada vez más relevante, en relación con servicios públicos locales.

Finalmente, hay que destacar el protagonismo que están llamados a desempeñar los órganos de defensa de la competencia, tanto la Comisión Nacional de la Competencia y de los Mercados como las autoridades autonómicas de competencia, en la salvaguarda de la libre competencia en aquellos ámbitos relacionados con los servicios que prestan las Entidades locales a los ciudadanos en los que participa la iniciativa privada.

\section{REFERENCIAS BIBLIOGRÁFICAS}

ALEMANY GARCÍAS, J. (2020): "Los modos de gestión del servicio público en el ámbito local”, en Revista General de Derecho Administrativo, núm. 53, págs. 1-39.

BALLESTEROS FERNÁNDEZ, A. (2001): "Los servicios públicos locales: servicios mínimos, servicios reservados, actuaciones económicas, servicios económicos de interés general y servicio universal”, en Revista de Estudios de la Administración Local (REALA), núm. 291, págs. 87-101. DOI: https://doi.org/10.24965/reala.vi291.9171.

BAÑO LEÓN, J. M. (2016): "La evolución del derecho de la competencia y su irradiación en el derecho público", en Revista de Administración Pública (RAP), núm. 200, págs. 295-314. DOI: https://doi.org/10.18042/cepc/ rap.200.15.

BARRERO RODRÍGUEZ, M. C. (2016): “La prestación de los servicios municipales mínimos en el nuevo art. 26 LBRL. La difícil interpretación de un precepto fundamental”, en Revista Española de Derecho Administrativo (REDA), núm. 170, págs. 21-52.

BOIX PALOP, A. (2014): "Sentido y orientación de la Ley 27/2013 de racionalización y sostenibilidad de la Administración local: autonomía local, recentralización y provisión de servicios públicos locales”, en Revista de Estudios de la Administración Local y Autonómica (REALA). Nueva Época, núm. 2, págs. 37-47. DOI: https://doi. org/10.24965/reala.v0i2.10199E.

CAMPOS SÁNCHEZ-BORDONA, M. (2004): "Los servicios de interés económico general y las corporaciones locales (una aproximación a los problemas que en el ámbito local plantea la prestación de los servicios de interés económico general)", en Cuadernos de Derecho Local (QDL), núm. 6, págs. 65-80.

CANEDO ARRILLAGA, M. (2014): "Derecho de la competencia, administración y descentralización”, en Nuevas Políticas Públicas: Anuario multidisciplinar para la modernización de las Administraciones Públicas, núm. 9, Ejemplar dedicado a: La reforma de la Administración Local, págs. 147-160.

CARLÓN RUIZ, M. (2016): "La constitucionalización del servicio público y su evolución en clave europea: entre mutación y reforma”, en Revista Española de Derecho Administrativo (REDA), núm. 177, págs. 227-256. 
REALA. Nueva Época - N.o 14, octubre 2020 - ISSN: 1989-8975 - DOI: https://doi.org/10.24965/reala.i14.10854 - [Págs. 69-87]

La progresiva apertura de los servicios públicos locales a la libre competencia

Roberto Galán Vioque

DEL GUAYO CASTIELLA, I. (2004): “La gestión de servicios públicos locales”, en Revista de Administración Pública (RAP), núm. 165, págs. 87-136.

ESPINOSA GARCÍA, J. (2011): "Derecho de la competencia y regulación en la actividad de las administraciones públicas", en GUILLÉN CARAMÉS, J. (coord.): Libre competencia y estado autonómico, págs. 197-219. Madrid: Thomson Reuters.

ESTEVE PARDO, J. (2017): "Perspectivas y cauces procedimentales de la remunicipalización de servicios", en Revista de Administración Pública (RAP), núm. 202, págs. 305-336. DOI: https://doi.org/10.18042/cepc/rap.202.11.

FERNÁNDEZ, T. R. (2016): "Reflexiones sobre la sostenibilidad de los servicios públicos, un nuevo principio general en gestación", en Revista de Administración Pública (RAP), núm. 200, págs. 439-450. DOI: https://doi. org/10.18042/cepc/rap.200.21.

FERNÁNDEZ GARCÍA, J. F. (2013): "Contratación administrativa y libre competencia”, en Revista Española de Derecho Administrativo (REDA), núm. 158, págs. 89-126.

GARCÍA RUBIO, F. (2015): "La iniciativa económica local tras la ley 27/2013, de 27 de diciembre, de racionalización y sostenibilidad de la administración local", en Revista de Estudios de la Administración Local y Autonómica (REALA). Nueva Época, núm. 3, págs. 9-33. DOI: http://dx.doi.org/10.24965/reala.v0i3.10238.

GONZÁLEZ BUSTOS, M. A. (2016): “Incidencia de la Ley 27/2013, de 27 de diciembre, de Racionalización y Sostenibilidad de la Administración Local en las competencias municipales en materia de mercado de abastos", en Revista de Estudios de la Administración Local y Autonómica (REALA). Nueva Época, núm. 6, págs. 79-91. DOI: https://10.24965/reala.v0i6.10389.

GONZÁLEZ TORROBA, P. (2017): Cuando el Ayuntamiento hace la Competencia. Derecho de la competencia y servicio público local. Madrid: Thomson Reuters Aranzadi.

GONZÁLEZ TORROBA, P. (2009): "Derecho de la competencia y servicio público local”, QDL - Quaderns de dret local, Fundación Democracia y Gobierno Local, núm. 20, págs. 160-173.

JIMÉNEZ SOTO, I. (2015): "Evolución y configuración de los servicios deportivos locales. Un acotamiento a propósito de la Ley 27/2013, de 27 de diciembre, de racionalización y sostenibilidad de la Administración Local", en Revista de Estudios de la Administración Local y Autonómica (REALA). Nueva Época, núm. 3, págs. 59-75. DOI: http:// dx.doi.org/10.24965/reala.v0i3.10240.

IBÁÑEZ GARCÍA, I. (2010): "Contratos públicos y defensa de la competencia”, en Actualidad Administrativa, núm. 1, págs. 1-3.

LENCE REIJA, C. (2015): "La iniciativa económica de las entidades locales y sus implicaciones para la libre competencia", en Revista Española de Derecho Administrativo (REDA), núm. 170, págs. 179-214.

MALARET GARCÍA, E. (2003): "Servicio público, actividad económica y competencia. ¿Presenta especificidades la esfera local?", en Revista de Estudios de la Administración Local (REALA), núm. 291, págs. 567-608. DOI: https:// doi.org/10.24965/reala.vi291.9190.

MARTÍN BAUTISTA, M. T. (2016a): "El principio de libre competencia en la contratación pública: influencias, restricciones y defensas (I)", en Contratación Administrativa Práctica: Revista de la Contratación Administrativa y de los Contratistas, núm. 142, págs. 30-47.

MARTÍN BAUTISTA, M. T. (2016b): "El principio de libre competencia en la contratación pública: influencias, restricciones y defensas (II)", en Contratación Administrativa Práctica: Revista de la Contratación Administrativa y de los Contratistas, núm. 144, págs. 33-49.

MONTOYA MARTÍN, E. (2010): "Algunas notas sobre la Ley de Autonomía Local de Andalucía: los servicios públicos y la iniciativa económica local”, en Cuadernos de Derecho Local (QDL), núm. 24, págs. 144-162.

ORTEGA BERNARDO, J. (2006): "Competencias, servicios públicos y actividad económica de los municipios", en Revista de Administración Pública (RAP), núm. 169, págs. 55-98.

PARICIO RALLO, E. (2013): "Los servicios funerarios en la nueva tipología de servicios municipales”, en Cuadernos de Derecho Local (QDL), núm. 33, págs. 77-89.

PAREJO ALFONSO, L. (2004): "Servicios públicos y servicios de interés general: la renovada actualidad de los primeros", en Revista de Derecho de la Unión Europea, núm. 7, págs. 51-68.

REBOLLO PUIG, M. (2019): "Acciones de competencia desleal contra actividad pública empresarial”, en Revista de Administración Pública (RAP), núm. 210, págs. 139-174. DOI: https://doi.org/10.18042/cepc/rap.210.06.

SALAS, J. (1990): "Régimen jurídico de las concesiones del servicio de suministro de gas por canalización", en Revista Española de Derecho Administrativo (REDA), núm. 65, págs. 17-46.

TORNOS MÁS, J. (2017): "Liberalización de servicios públicos locales y modalidades de actuación local en los sectores liberalizados", en Revista de Estudios de la Administración Local y Autonómica (REALA). Nueva Época, núm. 7, págs. 103-114. DOI: https://10.24965/reala.v0i7.10429.

VILLAR ROJAS, F. J. (2016): "Principios de sostenibilidad y estabilidad presupuestaria en la gestión de los servicios públicos locales”, en El Cronista del Estado Social y Democrático de Derecho, núms. 58-59, págs. 96-106. 